\title{
Erratum to "Epigenetic Modifications and Potential New Treatment Targets in Diabetic Retinopathy"
}

\author{
Lorena Perrone, ${ }^{1}$ Carmela Matrone, ${ }^{2}$ and Lalit P. Singh ${ }^{3}$ \\ ${ }^{1}$ UMUC Europe, 69126 Heidelberg, Germany \\ ${ }^{2}$ Department of Biomedicine, University of Aarhus, 8200 Aarhus, Denmark \\ ${ }^{3}$ Departments of Anatomy/Cell Biology and Ophthalmology, Wayne State University School of Medicine, Detroit, MI 48201, USA \\ Correspondence should be addressed to Lorena Perrone; perronelorenal@gmail.com \\ Received 17 November 2014; Accepted 23 November 2014; Published 30 December 2014 \\ Copyright (C) 2014 Lorena Perrone et al. This is an open access article distributed under the Creative Commons Attribution License, \\ which permits unrestricted use, distribution, and reproduction in any medium, provided the original work is properly cited.
}

In the paper titled "Epigenetic Modifications and Potential New Treatment Targets in Diabetic Retinopathy" the affiliation of Lorena Perrone was "EA 7281 R2D2, Medical School, Auvergne University, 63000 Clermont-Ferrand, France” and is corrected as above. 


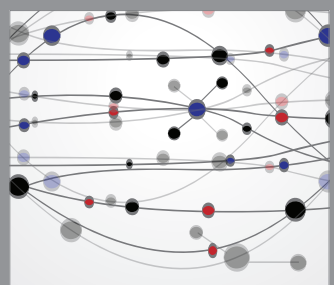

The Scientific World Journal
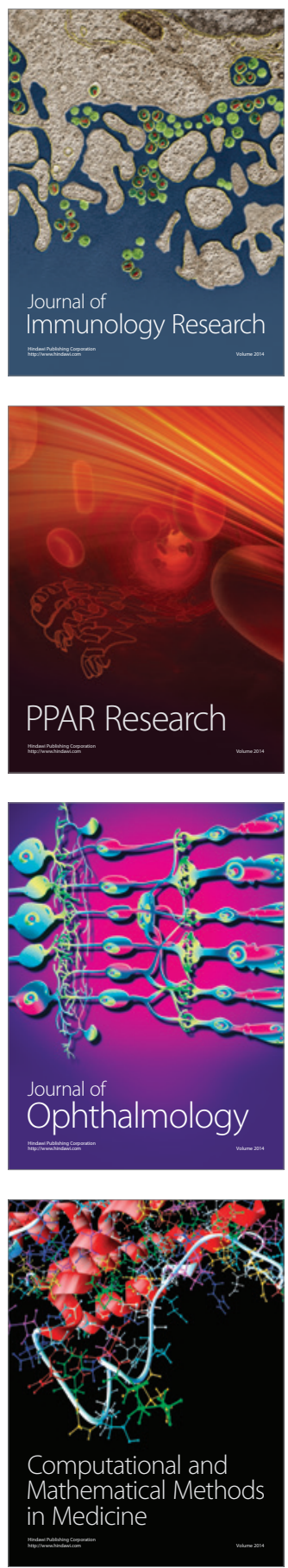

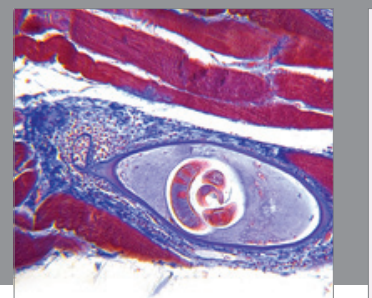

Gastroenterology

Research and Practice
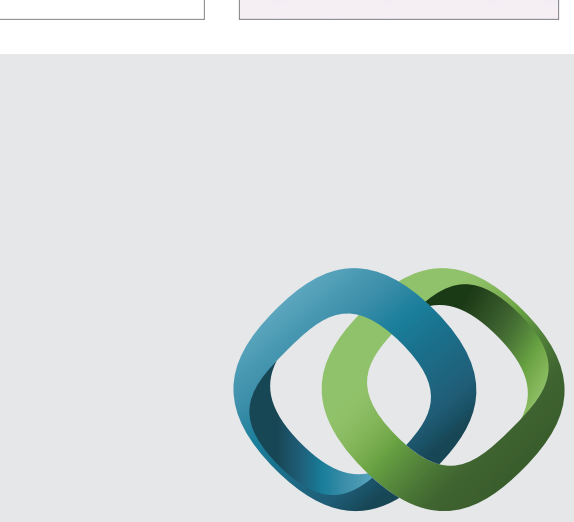

\section{Hindawi}

Submit your manuscripts at

http://www.hindawi.com
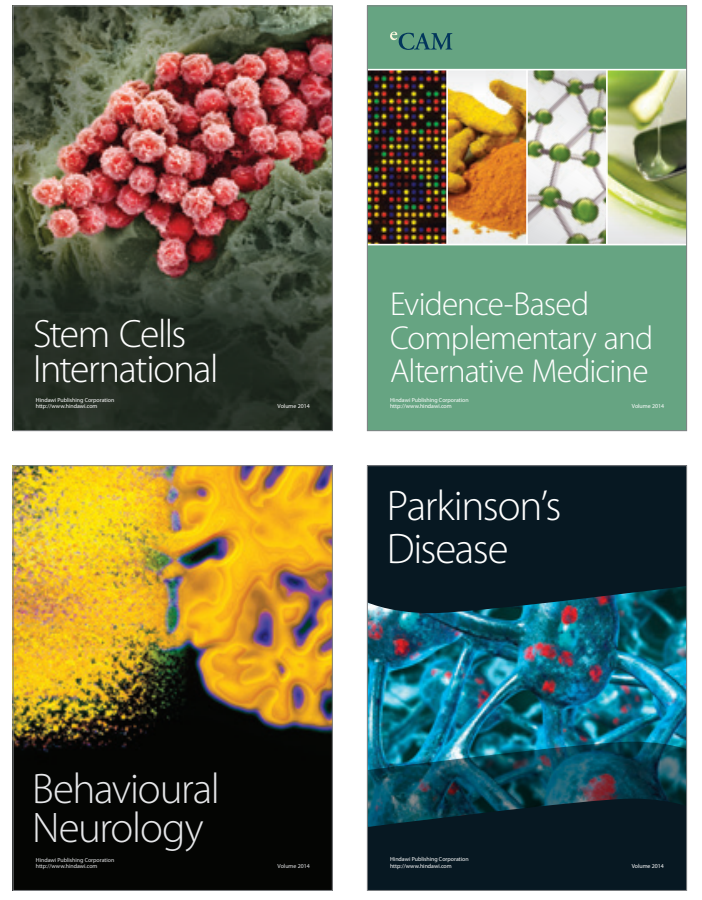
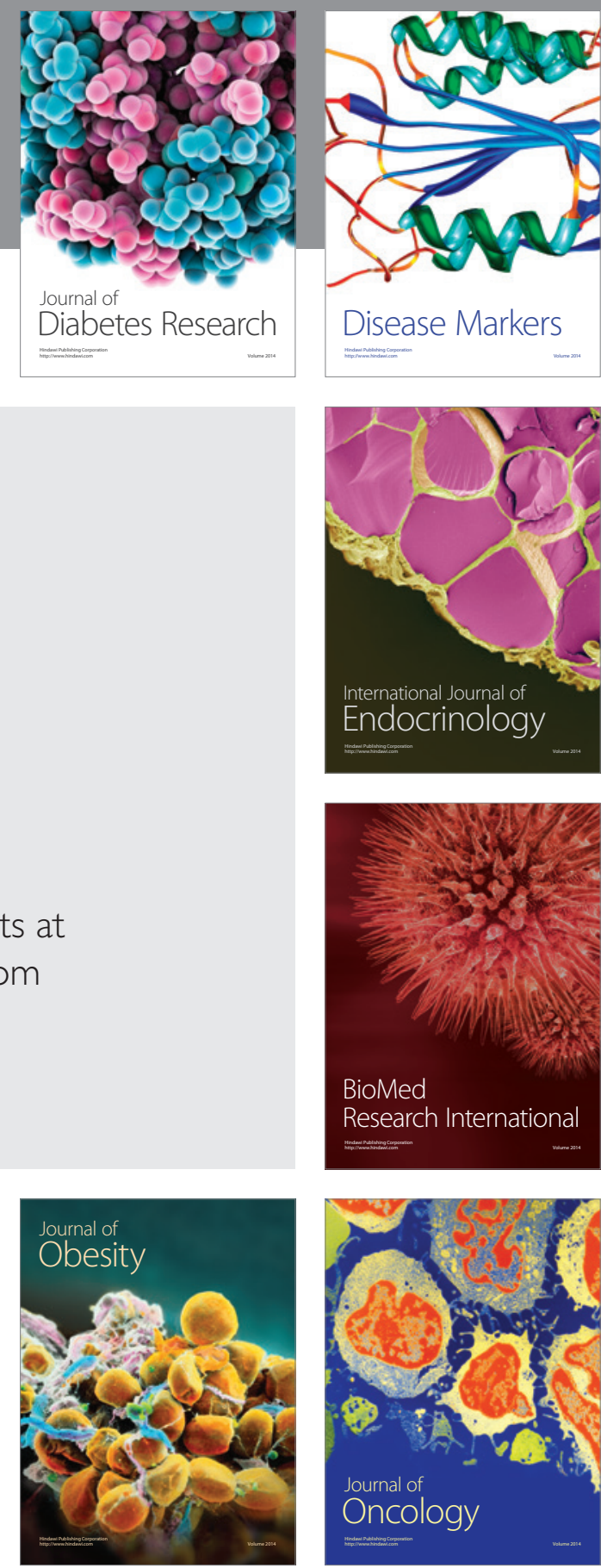

Disease Markers
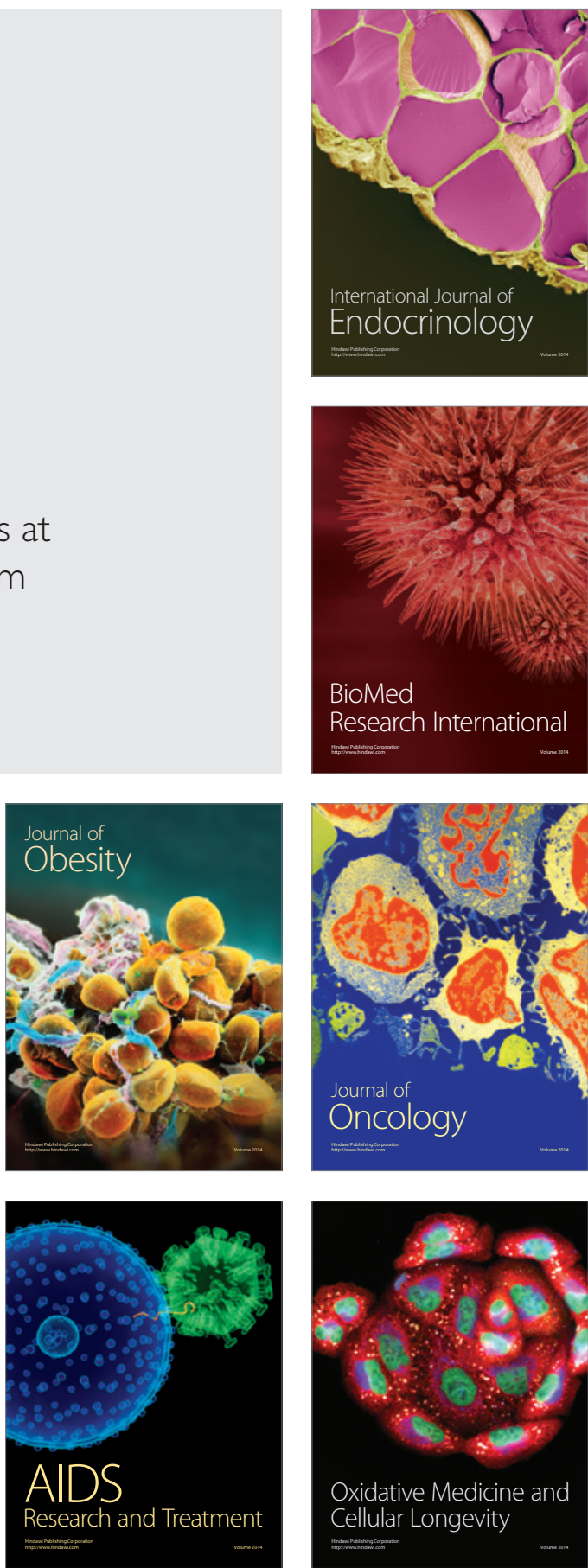